\title{
"AS BAHIAS E A COZINHA MINEIRA": A CONSTRUÇÃO DA IDENTIDADE NO MEIO ARTÍSTICO MUSICAL
}

\author{
Bianca Rosina Mattia* \\ Paulo Henrique Pergher ${ }^{* *}$
}

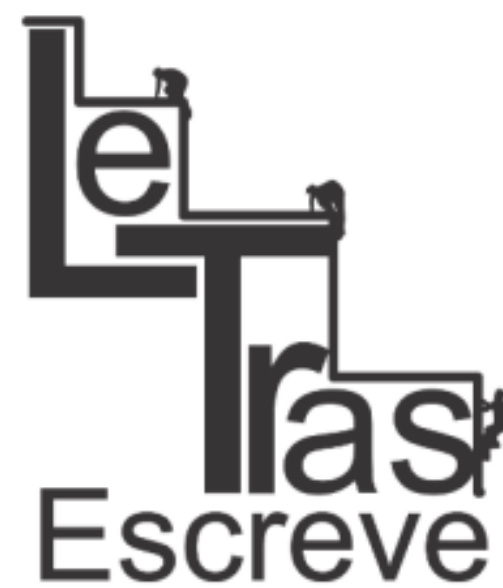

(ISSN 2238-8060)

Resumo: Stuart Hall (2011) escreve A identidade cultural na pósmodernidade partindo da afirmação de que as identidades modernas estão "descentradas". Isso porque, nos tempos da modernidade tardia, o que se percebe, segundo Hall, é a fragmentariedade do indivíduo moderno, não mais visto como um sujeito unificado e que, em razão disso, não encontra mais uma referência identitária estável na qual possa se encaixar. Nesse sentido, o presente artigo discute, à luz das teorias de gênero e das contribuições de Stuart Hall (2011) acerca da questão da identidade, o projeto musical do grupo As Bahias e a Cozinha Mineira, formado por duas mulheres transexuais, Assucena Assucena e Raquel Virgínia, e por um homem cisgênero, Rafael Acerbi. O objetivo é destacar como a construção da identidade pode se dar também no meio artístico musical. Para tanto, será, ainda, analisada uma das canções do álbum Mulher, intitulada Uma canção pra você (Jaqueta Amarela), destacando-se as relações entre esta composição e as teorias em foco.

Palavras-chave: Gênero. Identidade. Música. Transgeneridade.

Abstract: Stuart Hall (2011) writes The question of cultural identity based on the statement that modern identities are decentered. That's because during the late modernity what is perceived, according to Hall, is the fragmentarity of the modern subject, not seen as unified anymore and which can no longer find an stable identitary reference that he may fit. In that sense, the present paper discusses, based on Gender Studies and Hall's identity theory, the musical project As Bahias e a Cozinha Mineira, composed of two transgender women, Assucena Assucena and Raquel Virgínia, and a cisgender man, Rafael Acerbi. Our main objective is to enhance how identity construction may also be performed through the artistic and musical circles. Also, a song, entitled Uma canção pra você (Jaqueta Amarela), from the album Mulher, will be analyzed, highlighting its relations to the theory focused.

Keywords: Gender. Identity. Music. Transgender.

\footnotetext{
* Mestranda no Programa de Pós-Graduação em Literatura da Universidade Federal de Santa Catarina (UFSC). E-mail: biancamattia@gmail.com

** Graduando no curso de Letras Português da Universidade Federal de Santa Catarina (UFSC). E-mail: paulopergher@gmail.com
}

https://periodicos.unifap.br/index.php/letras

Macapá, v. 7, n. 3, 2\% semestre, 2017 
As Bahias e A Cozinha Mineira é o nome da banda composta pelas vocalistas transexuais Assucena Assucena e Raquel Virgínia, ambas apelidadas de "Bahia" no curso de História da Universidade de São Paulo, e pelo mineiro cisgênero, Rafael Acerbi. Apesar do apelido, apenas Assucena é baiana; Raquel é paulista. A banda desperta um novo cenário para a música popular brasileira. As canções trazem à tona questões de gênero e identidade, de preconceito contra mulheres e contra mulheres negras, além de evidenciarem, com isso, parte da própria realidade vivida por Assucena e por Raquel.

Mulher é o disco de estreia d'As Bahias. As canções, compostas pelas integrantes e inspiradas em Gal Costa, tratam de negritude, de transgeneridade e, especialmente, de mulheres. Do profano ao sa-

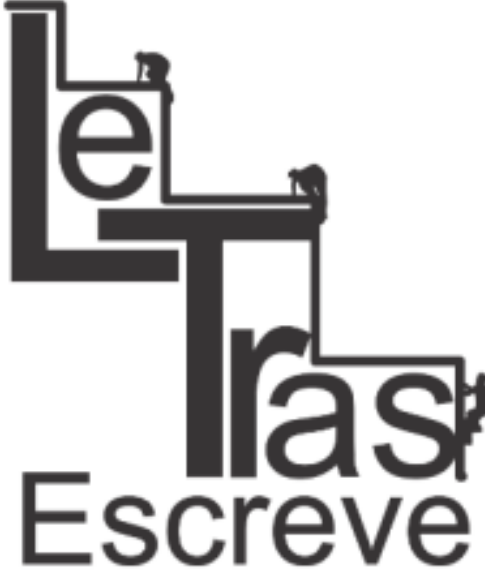

(ISSN 2238-8060) grado, do concreto ao universal, a busca em Mulher é a busca por linguagem, sem medo, como afirma Raquel na entrevista concedida a Amanda Rigamonti (2016); a busca pela desestabilização da linguagem cristalizada em estereótipos por uma sociedade patriarcalista, machista e moralista.

Ambas as compositoras e vocalistas assumem-se mulheres transexuais e afirmam que não intentam submeter-se à cirurgia. Assucena Assucena disse à jornalista Ana Ferraz, em matéria publicada na revista Carta Capital, que tal procedimento "Seria transferir a natureza da minha identidade para o cirurgião. A necessidade é outra, é minha identidade como ser social" (FERRAZ, 2016).

Nesse sentido, intentamos, neste ensaio, desenvolver uma reflexão acerca da construção da identidade, sobretudo da identidade das mulheres transexuais aqui representadas por Assucena Assucena e Raquel Virgínia, envolvendo, portanto, questões de gênero e sexualidade, mas, sobretudo pensando em como elas se empoderam no meio artístico musical para construir as suas próprias identidades.

https://periodicos.unifap.br/index.php/letras

Macapá, v. 7, n. 3, 2o semestre, 2017 
Além disso, a dialogar com a discussão da construção identitária, buscamos apresentar uma breve análise da tessitura poética de uma das canções do álbum Mulher, intitulada Uma canção pra você (Jaqueta Amarela).

Segundo Stuart Hall (2011), o conceito de identidade, além de complexo, é ainda pouco desenvolvido e compreendido na ciência social contemporânea, razão pela qual é complicado colocá-lo definitivamente à prova. Contudo, o autor ressalta que tal questão está sendo bastante discutida na teoria social e que, neste caso, "o argumento é o seguinte: as velhas identidades, que por tanto tempo estabilizaram o mundo social, estão em declínio, fazendo surgir novas identidades e fragmentando o indivíduo moderno, até aqui visto como um sujeito unificado." (HALL, 2011, p. 7).

Além disso, ainda conforme Hall, o argumento dos teóricos que acreditam estar a identidade em crise é o de que não temos mais a segurança da ideia de sujeitos integrados que antes tínhamos devido a ideias mais sólidas sobre nossas localizações enquanto indivíduos sociais. Assim, "esta perda do 'sentido de si' estável é chamada, algumas vezes, de deslocamento ou descentração do sujeito. Esse duplo deslocamento - descentração dos indivíduos tanto de seu lugar no mundo social e cultural quanto de si mesmos - constitui uma 'crise de identidade'." (HALL, 2011, p. 9).

A posição de Hall condiz com a afirmação de que "as identidades modernas estão sendo 'descentradas', isto é, deslocadas ou fragmentadas." (HALL, 2011, p. 8). O autor apresenta três concepções de identidades e ressalta em uma delas, qual seja, a do sujeito pósmoderno, que não é mais aquele sujeito que tem uma identidade "unificada e estável", mas sim um sujeito "composto não de uma única, mas de várias identidades, algumas vezes contraditórias ou não- 


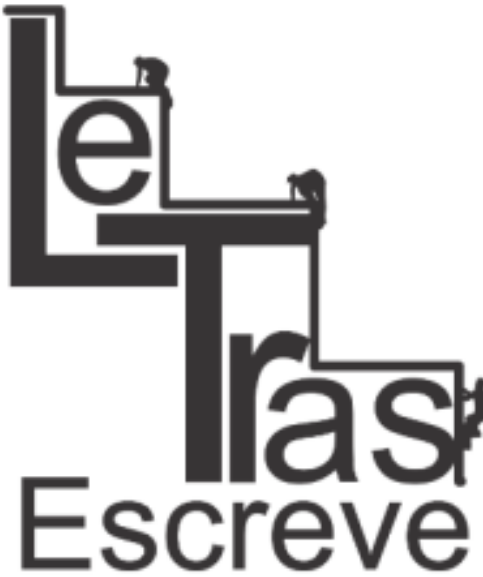

(ISSN 2238-8060)

resolvidas." (HALL, 2011, p. 12). Nesse sentido, Hall afirma que a identidade é definida historicamente e não de forma biológica, de modo que "o sujeito assume identidades diferentes em diferentes momentos, identidades que não são unificadas ao redor de um 'eu' coerente." (HALL, 2011, p. 13).

Com base nessas concepções acerca da construção da identidade apresentadas por Hall, também é possível estender a reflexão para as questões de gênero e sexualidade, sobretudo porque se fala aqui da construção da identidade de duas mulheres transexuais. Tais questões vão de encontro ao dualismo sexual que é imposto socialmente, traduzido em apenas duas possibilidades de sexo e, por conseguinte, de gênero: ou se é homem; ou se é mulher, e isso a partir de uma concepção biológica também dual dos órgãos genitais (ou se tem pênis; ou se tem vagina).

No rumo dessa discussão, Anne Fausto-Sterling (2001; 2002) destaca que rotular alguém homem ou mulher é uma decisão social, de modo que somente as nossas crenças sobre gênero são capazes de definir nosso sexo. Isso porque, para a autora, a complexidade de nossos corpos não permite respostas claras sobre a diferença sexual. Razão pela qual o que é possível é a utilização do conhecimento científico para contribuir na tomada de decisão, mas a ciência não é quem determina o sexo, o determinante são as nossas crenças sobre gênero.

Ademais, sobre a imposição da biologia para determinação do sexo, Fausto-Sterling $(2001 ; 2002)$ afirma que a biologia é também um discurso cultural, faz parte de discursos culturais, portanto, de modo que a crença em dois gêneros acaba por levar à crença em dois sexos. A autora observa, ainda, que tudo passa por aparatos interpretativos, razão pela qual se impõe questionar os dualismos, ou melhor, 


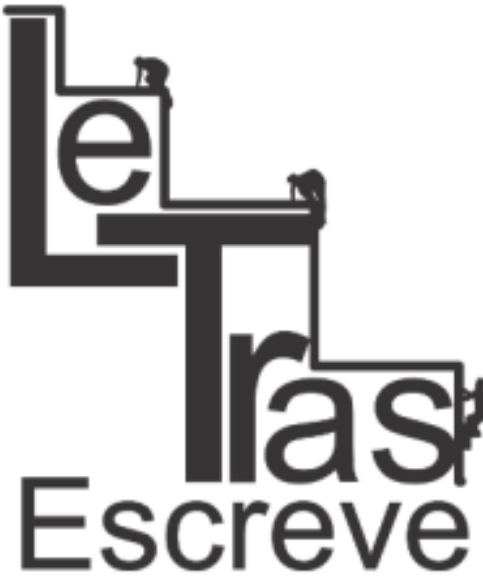

(ISSN 2238-8060) indagar o motivo pelo qual sempre se faz uso de dualismos para interpretar o mundo.

O debate sobre gênero, como propõe Guacira Lopes Louro (2014), também está inserido no campo do social. Para a autora, "o gênero se constitui com e sobre corpos sexuados, ou seja, não é negada a biologia, mas enfatizada, deliberadamente, a construção social e histórica produzida sobre as características biológicas." (LOURO, 2014, p. 22). Assim, o debate sobre gênero insere-se no lugar onde são construídas e reproduzidas as relações - desiguais - entre os sujeitos. A proposta, como destaca Louro, é buscar justificativas para as desigualdades, porém, não nas diferenças biológicas, mas no campo social, na história, nas condições de acessibilidade aos recursos sociais e nas maneiras de representação. Dessa forma, tem-se que é no âmbito das relações sociais que se constroem os gêneros.

Ao se assumirem como mulheres transexuais, Assucena e Raquel enfrentam, em função da predominância - que ainda impera em nossa sociedade - do dualismo sexual e de gênero, forte preconceito. Assucena Assucena afirma que "Uma mulher trans sofre abusos diferentes de uma cisgênero. [...]. Evito sair de saia e vestido para não ser ridicularizada." (FERRAZ, 2016). Por sua vez, Raquel Virgínia destaca: "Nos dizem coisas horríveis o tempo todo. Os olhares não mais me incomodam". E é na maneira como se apoderam de seus corpos que Raquel Virgínia, como afirma Ana Ferraz (2016),

aprendeu a se defender por meio de uma atitude capaz de intimidar o agressor. Uma espécie de campo de força a repelir os incomodados com sua imagem de mulher negra e forte, cabelos loiros puxados em tranças, maquiagem a realçar o rosto bonito, acessórios a passar a mensagem de que o feminino mora ali, e sempre morou. 


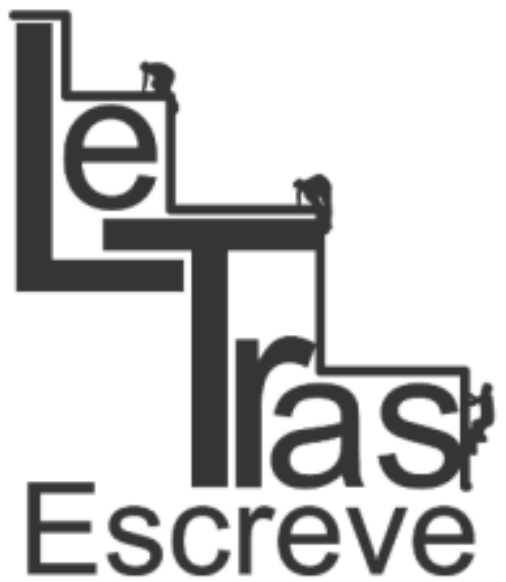

(ISSN 2238-8060)

No palco não é diferente. Seus corpos também ganham a cena aliados às canções e performances desenvolvidas por elas. Assim como aponta Sonia Maluf (2002) ao falar sobre a personagem Agrado, no filme Tudo sobre minha mãe, de Pedro Almodóvar, elas não buscam o ocultamento. Tal como Agrado, Assucena e Raquel não fazem de conta que são mulheres e que sempre foram. "Sua afirmação pública é feita pela exibição de seu corpo exatamente pelo que ele é" (MALUF, 2002, p. 145). Para Maluf, a autenticidade do corpo da personagem Agrado está justamente "no produto de sua criação, da intervenção de seu desejo, de uma agência própria." (2002, p. 146). Da mesma forma é possível identificar como Assucena e Raquel assumem seus corpos: com a maquiagem, os cabelos, as unhas pintadas, as roupas que vestem. Maluf destaca que

\begin{abstract}
Agrado não se transforma para ocultar uma identidade anterior e autêntica e mostrar outra, falsa mas que finge ser verdadeira. Quando lhe é dado o palco, ela apresenta o caráter fabricado de seu corpo. Ao romper com a oposição entre o falso e o verdadeiro, ela também rompe com outra oposição essencialista: natureza e antinatureza. [...]. É a partir das transformações feitas em seu corpo, e principalmente da fala sobre esse corpo, que só ganha existência enquanto corpo do qual se fala, que Agrado aparece como sujeito. (2002, p. 146).
\end{abstract}

Assucena e Raquel não querem ocultar suas identidades, mas sim destacá-las/assumi-las ainda mais por meio do espaço musical, lugar onde seus corpos falam/cantam, dão voz a quem elas se constroem, inclusive naquele momento no palco. Não se trata de uma encenação de algo que não corresponde com o que são, mas, justamente o contrário. Trata-se de uma afirmação do que também naquele momento elas são. Suas identidades, contudo, não se restringem a dizer que são mulheres, uma vez que elas cantam as diversas

https://periodicos.unifap.br/index.php/letras

Macapá, v. 7, n. 3, 2o semestre, 2017 


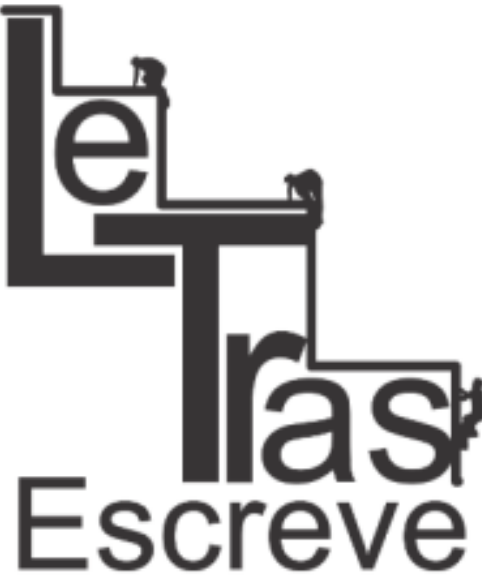

(ISSN 2238-8060) mulheres. No momento da performance musical, assumem-se várias: mulheres que não somam características, mas que resultam de atravessamentos, interseccionalidades, como afirma Adriana Piscitelli (2008).

Para Piscitelli (2008), somos o resultado de atravessamentos e não de somas. Com isso, é possível dizer, por exemplo, que a mulher está nos espaços hifenizados. Para a autora, as interseccionalidades permitem pensar as articulações entre gênero, sexualidade, raça e etnicidade/nacionalidade. As interseções entre essas categorias dotam de sentido a percepção que se tem sobre elas e podem contribuir para a destruição do pensamento heterossexual, bem como para a recusa à biologização do feminino, como afirma Piscitelli (2008). Nesse sentido, pode-se pensar na construção das identidades do sujeito pós-moderno, como incialmente destacamos com a análise de Hall (2000), ou seja, um sujeito fragmentado, não estável, justamente porque é marcado por atravessamentos, interseccionalidades. Assucena e Raquel não são só mulheres, mas são mulheres transexuais, são mulheres transexuais negras, são mulheres transexuais negras cantoras ...

E o que cantam? Jean Wyllys denomina "MPBTrans", um "movimento que se contrapõe, em termos artísticos, ao retorno dos discursos conservadores, reacionários e fundamentalistas religiosos à hegemonia política no país." (WYLLYS, 2016). Além disso, Wyllys afirma que há três características essenciais da MPBTrans:

a) suas estrelas pulverizam as fronteiras de gênero, adotando visual andrógino ou assumindo identidades de gênero policiadas; b) compõem e cantam letras de músicas que evocam a política do corpo e identitária, com referências mais ou menos explícitas às minorias sexuais, étnicas e religiosas; e c) têm relação umbilical com a internet e as redes sociais 
digitais (ou emergiram daí para abrir espaços nas mídias tradicionais ou trocaram escassos espaços nestas por lugares de destaque entre os internautas). (WYLLYS, 2016)

Em As Bahias e A Cozinha Mineira, Assucena Assucena e Raquel Virgínia também constroem suas identidades transexuais no espaço musical. Jean Wyllys observa que

o prefixo trans se refere à condição de quem partiu, mas ainda não chegou; de quem se deslocou deliberadamente de um lugar em direção a outro, mas ainda está a caminho, em trânsito; de quem deixou uma casa, um ethos ou identidade para trás, mas ainda está sem abrigo e em construção de uma nova casa ou identidade ou de um novo ethos; de quem está em transformação. (2006)

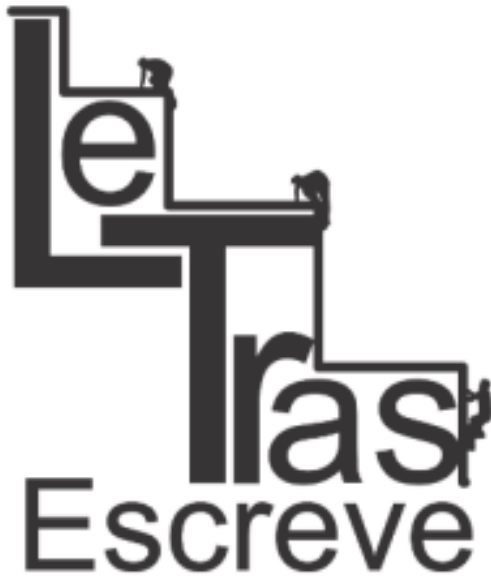

(ISSN 2238-8060) do por Jean Wyllys no fragmento acima citado. A percepção de Wyllys acerca da transexualidade como uma condição de alguém que está no meio do caminho para alcançar uma identidade equivoca-se, sobretudo tendo como contraponto a construção da identidade constantemente alterada e deslocada, conforme as considerações apresentadas por Hall (2000). Assim, o/a transexual não está no meio do caminho para alcançar uma identidade, mas ele/ela já a tem, por um momento que pode ser longo ou curto, mas isso não significa que está em busca de uma identidade, tampouco que, por ser trans, ainda não sabe o que é.

Contudo, a afirmação social dessa identidade nem sempre é tranquila, antes o contrário. Ao analisarmos as canções d'As Bahias e a Cozinha Mineira, temos em Uma canção pra você (Jaqueta Amare- 


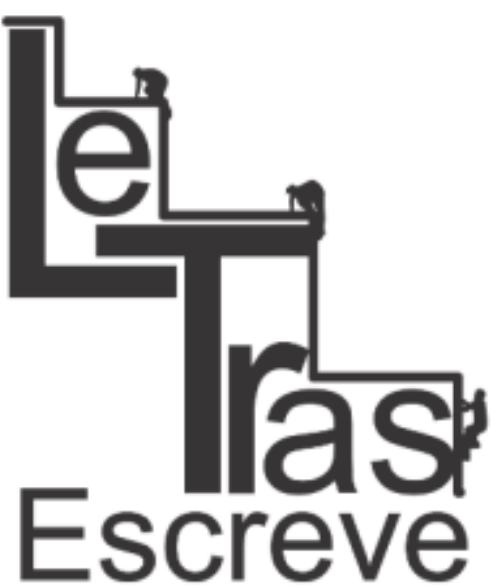

(ISSN 2238-8060) $(a)^{1}$, a nona canção do disco Mulher, o momento de revelação, o ato de dizer, em que muitos gays, lésbicas, trans, frente à família tradicional, à sociedade conservadora, acabam por se engendrar temerosamente. A norma, que condiz com um sistema binário sexo/gênero, como discutido anteriormente, e, por conseguinte, o desejo pelo $o$ posto, é aflitiva para aqueles que são distintos dela. Responder à família e à sociedade, em tal situação, é ter a norma como parâmetro dentro do contexto específico. A dificuldade, pois, assim como a angústia e a aflição frente ao evento, reside justamente no fato de tais espaços - família, amigos, professores - recorrerem a narrativas largamente reproduzidas por instituições de grande poder. Dizer, em tal situação, é, todavia, a possibilidade de recriar tais narrativas para si e para com o outro.

Na música em questão, inicialmente, o sujeito-lírico, deparando-se com a imagem de outrem que não o compreende, escolhe a trama de seu dizer e compõe uma canção tomando por objeto central a jaqueta amarela. A canção assim inicia:

\section{Eu vou cantar Uma canção pra você Feita da tua imagem Diante da minha face}

Ah se, ah se você pudesse entender Baby eu vou cantar Uma canção Uma canção pra você
A jaqueta amarela
Sobre a cama
Você sabe qual é!
Você sabe qual é!

A jaqueta amarela, objeto indiferente, num primeiro momen-

\footnotetext{
${ }^{1}$ Disponível em: <https://www.youtube.com/watch?v=Bxbuqll1F0w>.
} 


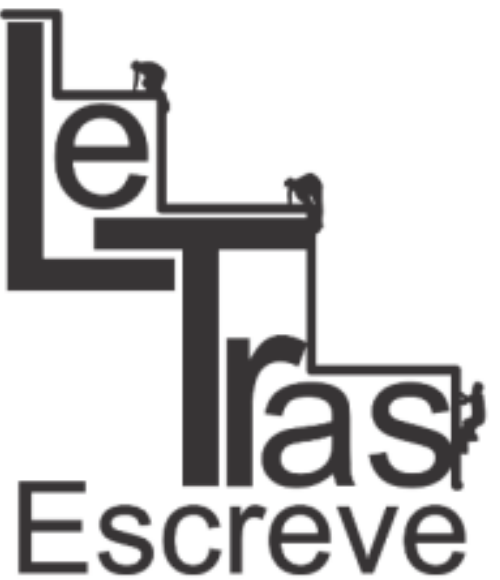

(ISSN 2238-8060)

to, peça de roupa comum, torna-se o foco da canção: "Você sabe qual é!". Transpassada por discursos vários, a jaqueta amarela deixa de representar uma simples indumentária e torna-se, em meio à cultura e à cena, símbolo para além da cor, retomando os fulcrais rosas e azuis dos bibelôs infantis. O amarelo, na canção, é a cor que o teu abraço não sentiu, por não se perceber que ali residia outro: um corpo que dorme sobre um lido jornal. Um corpo, ainda, desigual. Se pensarmos no par sexo/gênero, que na cultura tradicional é entendido em função de igualdade, o corpo desigual surge enquanto rompimento de tal paradigma. Sem jaqueta amarela, entretanto, igual. Igual aos corpos que circulam delimitados pelas normativas tradicionais de gênero: um despedaço de amor. Em tal contexto, mina-se, infalivelmente, o próprio afeto, em cada simples lugar que existia.

\author{
A jaqueta amarela \\ Que a cor do teu abraço não sentiu \\ O frio... Através da janela \\ Alguém sente lá fora, amor! \\ A dor, a dor \\ Da coberta aberta sobre a cama \\ Sobre um lido jornal dorme um corpo \\ Dorme um corpo \\ Desigual \\ Igual! Sem jaqueta amarela \\ Igual um despedaço de amor \\ Que em cada canto de um teto \\ Destila caçada do afeto em cada cor \\ Cada carro \\ Cada barro de pele num jarro de flor \\ Cada sarro que mera pinga \\ Cada cama que não me ama! Ama! Ama! Ama!
}

Cada espaço, cada carro, cada jarro, cada cama, deixam de representar o amor, passando a representar o contrário: a impossibilidade. Logo, surge a questão: "Quem nos media / Dia-a-dia o nosso 
sexo amor"? Quem ou o que se postula entre nós e nos impossibilita? E as possíveis respostas são várias: o anexo, ou o fato de eu ter um pênis; o nexo, ou se fazemos sentido juntxs, ou o que pensam de nós; o " $x$ " da nossa dor, ou o fato de termos nascido e nos construirmos de formas distintas. O sujeito-lírico, todavia, propõe seu sentimento em outros termos, pois aposta o amor no jogo entre cartas, cervejas, fogo e queijo coalho. E, nesse jogo, afirma-se dama de paus, mulher trans, sem que tal afirmação seja a negação do outro ou de sua relação e história.

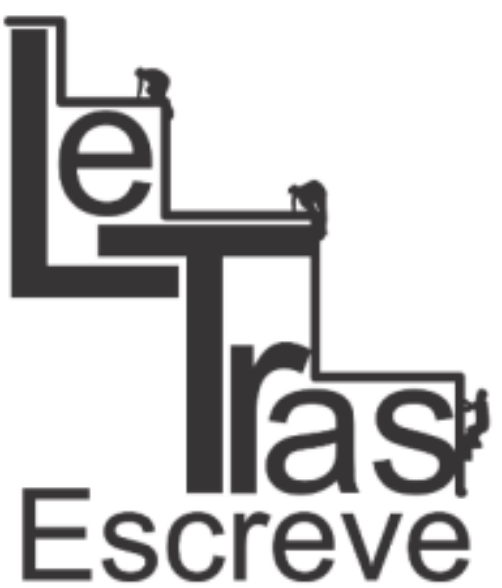

(ISSN 2238-8060)
Eu vou cantar

Uma canção pra você

Feita da tua imagem

Diante da minha face

Ah se, ah se você pudesse entender

Baby eu vou cantar

Uma canção

Uma canção..

Quem nos media

Dia-a-dia o nosso sexo amor

$O$ anexo

O nexo

O "x" da nossa dor

O amor eu aposto no jogo entre cartas, cervejas, fogo e queijo coalho

No baralho jogo os "As"

Te embaralho, sou dama de paus

(Caralho!)

Com a canção exposta, entre dedos e anéis, a faca e o beijo na mão, o sujeito-lírico reitera sua posição: Sou teu sim! Não teu não! Não sou tua - ou nossa - impossibilidade, pois sou tua, tão sua, sou esta canção!

https://periodicos.unifap.br/index.php/letras

Macapá, v. 7, n. 3, 2o semestre, 2017 
A canção está posta à mesa

Entre dedos e anéis, a faca e o beijo na mão

Sou teu sim!

Não teu não!

Sim sou tua, tão sua, sou esta canção!

Sou teu sim!

Não teu não!

Sim sou tua, tão sua, sou esta canção!

Eu vou cantar

Uma canção pra você

Feita da tua imagem

Diante da minha face

Ah se, ah se você pudesse entender

Oh baby! Baby eu vou cantar

Uma canção

Uma canção pra você

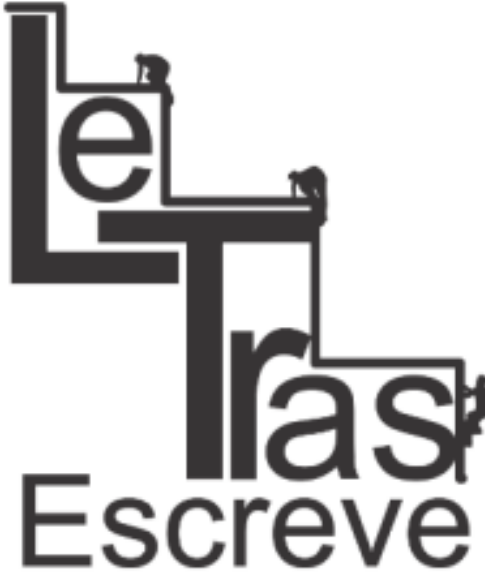

(ISSN 2238-8060)

O sujeito-lírico, enfim, expõe sua canção, sem ter uma réplica. A réplica, pois, envolveria outro contexto e poderia, infelizmente, negar o próprio. As histórias que derivam de tais eventos são as mais variadas possíveis. O documentário Bichas ${ }^{2}$, disponível no sítio Youtube, por exemplo, traz diversos depoimentos de homossexuais acerca do momento em que conversaram sobre a questão com suas famílias. Judith Butler, ainda, em entrevista de Peter Osborne e Lynne Segal, discute que não só a norma da heterossexualidade é tênue, como também todas as normas sexuais. Segundo a autora:

Não é só a norma da heterossexualidade que é tênue. São todas as normas sexuais. Eu penso que toda posição sexual é fundamentalmente cômica. Se você diz "eu só posso desejar X", o que você imediatamente fez, ao tratar do desejo de forma exclusiva, foi criar toda uma série de posições que são impensáveis do ponto de vista da sua identidade. Agora,

\footnotetext{
${ }^{2}$ Cf. BICHAS, o documentário. Dirigido por Marlon Parente. Com participação de Bruno Delgado, Igor Ferreira, Italo Amorim, João Pedro Simões, Orlando Dantas e Peu Carneiro. 2016. Disponível em: <https://www.youtube.com/watch?v=0cik7j-0cVU>. Acesso em: 05 dez. 2016.
}

https://periodicos.unifap.br/index.php/letras

Macapá, v. 7, n. 3, 2o semestre, 2017 
eu penso que um dos aspectos essenciais da comédia emerge quando você acaba por ocupar a posição que você anunciou como impensável. Isso é engraçado. Há uma terrível autosubversão nisso. (BUTLER, 1994, tradução nossa ${ }^{3}$ ).

A canção em destaque nos ilustra justamente esse movimento exposto por Butler: a partir do dito eu gosto de $X$, ou só posso desejar $X$, e das premissas que o acompanham - o $X$ do sexo, do nexo e do anexo - o sujeito-lírico se vê frente ao impensável. E o impensável acaba por desestabilizá-lo quando ocorre a subversão, o momento em que o sujeito-lírico revela que é uma dama de paus. O outro, o tu, - uma mulher, se pensarmos normativamente - diria: "Eu gosto de

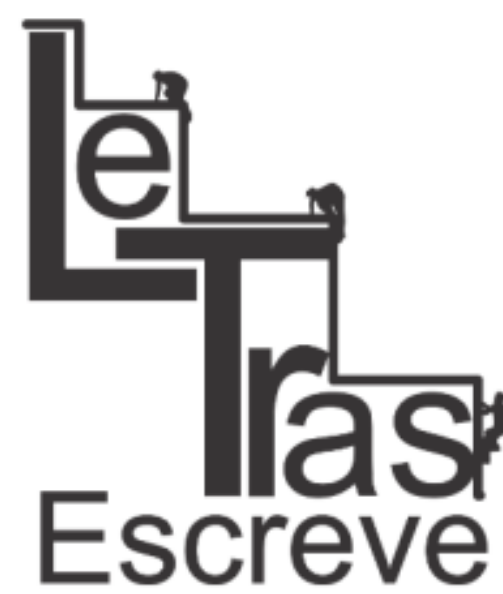

(ISSN 2238-8060) homens". Na canção, diria também "Eu gosto de você". Agora, a questão seria: como conciliar tal mudança? Se gostar de homens é uma premissa da minha identidade, consequentemente não posso gostar de você. A normatividade, assim, delineia corpos e desejos, tornando-os normais ou anômalos, sentenciando-os a premissas discursivas que irrompem em cenas nunca antes experienciadas. TrabaIhos tais, como o das Bahias, são extremamente caros, na medida em que questionam espaços cotidianos e comuns, nos quais nossos preconceitos se engendram e se fixam, como é o caso da jaqueta amarela.

Retomando Hall (2011), convém destacar, em linhas finais, que a construção identitária do sujeito pós-moderno afirma-se, também, no fato de que "dentro de nós há identidades contraditórias, empurrando em diferentes direções, de tal modo que nossas identificações

\footnotetext{
${ }^{3}$ No original: "It's not just the norm of heterosexuality that is tenuous. It's all sexual norms. I think that every sexual position is fundamentally comic. If you say "I can only desire X", what you've immediately done, in rendering desire exclusively, is created a whole set of positions which are unthinkable from the standpoint of your identity. Now, I take it that one of the essential aspects of comedy emerges when you end up actually occupying a position that you have just announced to be unthinkable. That is funny. There's a terrible self-subversion in it."
} 


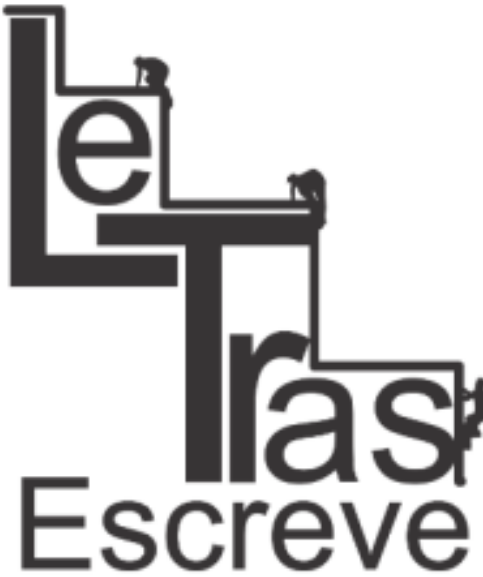

(ISSN 2238-8060) estão sendo continuamente deslocadas." (HALL, 2011, p. 13). Nesse sentido, o trabalho d'As Bahias e a Cozinha Mineira, objeto de análise para o desenvolvimento da reflexão aqui apresentada, desperta para esta percepção de que nada é estático e estável, nem mesmo a identidade, bem como de que não há meios de se perpetuar dualismos em questões de gênero e sexo, porque este - o sexo biológico - também não dá conta, digamos assim, de sustentar tal dualismo. A complexidade do corpo biológico não se limita ao dualismo imposto. Além disso, a construção da identidade é também social - ou totalmente social -, marcada pelo desenvolvimento social e cultural e, dessa forma, com mais razão, incapaz de permanecer estável e unificada.

As maneiras de buscar a afirmação identitária, não no sentido de uma afirmação absoluta, mas de uma afirmação em um dado momento da existência social do indivíduo, é buscada e desenvolvida em diversos ambientes, inclusive culturais, como é o caso da música, que aqui apresentamos pelo exemplo da banda As Bahias e A Cozinha Mineira e suas integrantes, Assucena Assucena e Raquel Virgínia.

\section{Referências}

BICHAS, o documentário. Dirigido por Marlon Parente. Com participação de Bruno Delgado, Igor Ferreira, Italo Amorim, João Pedro Simões, Orlando Dantas e Peu Carneiro. 2016. Disponível em: $<$ https://www.youtube.com/watch?v=0cik7j-0cVU>. Acesso em: 05 dez. 2016.

BUTLER, Judith. "Gender as Performance: An Interview with Judith Butler." Radical Philosophy, 67, Summer 1994. Disponível em: <http://www.theory.org.uk/but-int1.htm>. Acesso em: 04 dez. 2016. FAUSTO-STERLING, Anne. Dualismos em duelo. Cadernos Pagu, v.

https://periodicos.unifap.br/index.php/letras

Macapá, v. 7, n. 3, 2o semestre, 2017 


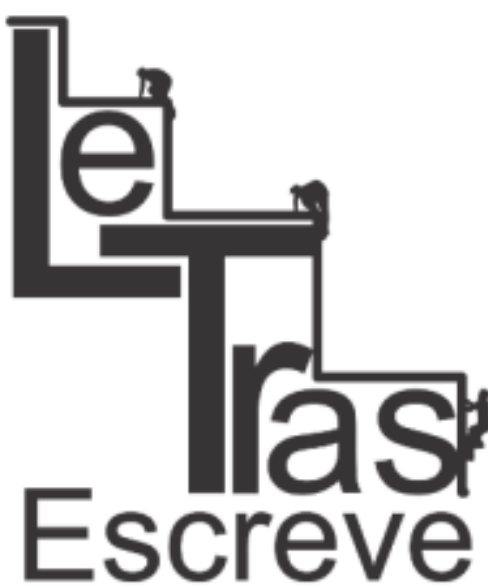

(ISSN 2238-8060)

17/18, 2001/2002, p. 9-79.

FERRAZ, Ana. O feminino mora aqui. In: Carta Capital. Publicado em 01 novembro de 2016. Disponível em: <http://www.cartacapital.com. br/revista/924/o-feminino-mora-aqui>. Acesso em: 22 nov. 2016.

HALL, Stuart. A identidade cultural na pós-modernidade. Tradução de Tomaz Tadeu da Sila e Guacira Lopes Louto. 11. ed. Rio de Janeiro: DP\&A, 2011.

LOURO, Guacira Lopes. Gênero e sexualidade: pedagogias contemporâneas. Pro-Posições, v. 19, n. 2, 2014, p. 74-85.

MALUF, Sonia. Corporalidade e desejo: Tudo sobre minha mãe e o gênero na margem. Revista Estudos Feministas, UFSC, Florianópolis, v. 10, n. 1 , p. $143-153,1^{\circ}$ semestre 2002.

PISCITELLI, Adriana. Interseccionalidades, categorias de articulação e experiências de migrantes brasileiras. Sociedade e Cultura, v. 11, n. 2, p. 263-274, jul-dez 2008.

RIGAMONTI, Amanda. "o que quiseram fosco está brilhando" - as bahias e a cozinha mineira falam sobre seu primeiro disco, "mulher". Entrevista com o grupo. 2016. Disponível em: <http://www.itaucultu ral.org.br/explore/blogs/fala-com-arte/o-que-quiseram-fosco-estabrilhando-as-bahias-e-a-cozinha-mineira-falam-sobre-seu-primeirodisco-mulher/>. Acesso em: 05 dez. 2016.

WYLLYS, Jean. MPBTRANS: a transformação da música brasileira. Revista TRIP. Publicado em 27 de outubro de 2016. Disponível em: <http://revistatrip.uol.com.br/trip-transformadores/trip-transforma dores-2016-jean-wyllys-fala-sobre-um-novo-movimento-musical-o-m pbtrans>. Acesso em: 22 nov. 2016.

Artigo recebido em 04/05/2017

Aceito em 09/09/2017

https://periodicos.unifap.br/index.php/letras

Macapá, v. 7, n. 3, 2o semestre, 2017 